\title{
EUROPEAN AIRSPACE FRAGMENTATION TYPOLOGY
}

\author{
Zvonimir Rezo ${ }^{1}$, Sanja Steiner ${ }^{2}$ \\ ${ }^{1}$ Croatian Academy of Sciences and Arts, Traffic Institute, Zagreb, Kušlanova 2, Croatia \\ ${ }^{2}$ University of Zagreb, Faculty of Transport and Traffic Sciences, Vukelićeva 4, Zagreb, Croatia
}

Received 26 October 2019; accepted 20 December 2019

\begin{abstract}
By reviewing bibliography sources addressing airspace design and system performances, it's evident that airspace fragmentation decreases the efficiency of European Air Traffic Management (ATM) system. Although it's often mentioned, a minor progress has been made to describe this issue more in-depth. Therefore, this research was carried out with the purpose to determine typology of European airspace fragmentation and to identify topic issues that need to be addressed in further research. The research is focused on literature review and analysis of European airspace design. As result of conducted analysis, five airspace fragmentation types have been defined and described. Accordingly, spatial distribution and temporal consistency of airspace fragmentation types were depicted as well as their similarities and differences. In addition, this research identifies airspace fragmentation type requiring additional study. Lastly, this research paper aims to contribute to better understanding of ATM system arrangement and simplify strategic planning at national and regional level in terms of capacity, cost-efficiency, environment and safety as four pillars of future development of European ATM system.
\end{abstract}

Keywords: air traffic management, European airspace, fragmentation, typology.

\section{Introduction}

In Europe, before 1987, national air traffic markets were protected, regulated and fragmented with a goal to safeguard individual national interests (Kawagoe, 2008). That time was mainly characterized by different state's financial aids and subsidies to the state-owned companies, inconsistent national and regional regulations and operational constraints. Significant improvement change occurred after successful resolution of prerequisites for future economic development in terms of deregulation and implementation of three packages of market liberalisation measures (Janić, 1997; Button, 2001; Ozmec Ban and Škurla Babić, 2018). However, although prerequisites for future economic development have been fulfilled, European ATM system continued to be fragmented on base of national boundaries.

Considering the forecasts referring future air traffic increase in Europe (Cook, 2016), the need for better Air Navigation Service quality at lower cost is becoming increasingly important topic between stakeholders of European ATM system (Skyway Magazine, 2018). Airspace represents a limited resource (Finger, 2017), but in Europe it's still organised in a fragmented way (Stankūnas and Kondroška, 2012; Oster and Strong, 2017; Getimēs and Kaukalas, 2007; Neiva, 2015). Nowadays, if it's not specified differently by cross-border arrangements,

${ }^{1}$ Corresponding author: promet@hazu.hr 
every time when aircraft transits over national boundary it is serviced by different Air Navigation Service Provider (ANSP). That often leads to the situations in which aircraft are being guided on base of different operational requirements and restrictions (European Court of Auditors, 2017). In such way fragmentation limits airspace capacity, adversely affects the environment, increases operational costs and above all, potentially affects safety (Nava-Gaxiola and Barrado, 2016). Moreover, it's expected that airspace fragmentation will continue to adversely affect European ATM system's efficiency (Budd and Ison, 2016).

Even though fragmented design of European airspace is quite a recognizable problem (which is frequently mentioned within the ATM community), still there are many unanswered questions requiring comprehensive analysis with a view to provide appropriate answers and improvement guidelines. By reviewing literature this research aims to define European airspace fragmentation typology and to answer following research questions - Which fragmentation types exist?; What are the differences between them?; How they can be displayed?; Which types are more apparent than others?; How much do they spatially and temporally vary?; When did some types began to appear?; Which fragmentation types have been studied the most?; and finally Which fragmentation types require further research?

\section{European Airspace Fragmentation Status}

During past few years European ATM system has shown high volatility level, especially when it faced with different and unpredicted events caused by variability of air traffic flow induced by economic (Macário and Van de Voorde, 2009; Dobruszkes and Van Hamme, 2011) or geopolitical crisis (Szalai, 2018), serious weather or ash caused network disruptions (Schultz et al., 2018; Alemanno, 2010) etc. This has resulted with the fact that nowadays design of European airspace is frequently characterized as "zigzagging", "inefficient" or "fragmented" (FABEC, 2019). In order to minimize these characteristics SESAR (Single European Sky ATM Research) program have been establish (SESAR Joint Undertaking, 2019a) and various of regulations were introduced by European Commission (European Commission, 2019). While there are notable network improvements in terms of first two characteristics (Network Manager, 2018), third one still poses a hardly overcoming issue requiring further improvements (SESAR Joint Undertaking, 2019b). Accordingly, there is huge need for political, operational and technical interventions in order to further optimise design of European airspace.

Airspace fragmentation problem have been officially recognized by the European Commission yet in 1996 arguing that the European Union "cannot keep the frontiers in the sky that it has managed to eliminate on the ground" (European Commission, 1996). Although a long time has passed since then, clearly recognizable constraints associated with fragmentation problem are still seriously impeding European air traffic market' ability to grow sustainably and competes internationally (European Commission, 2017a). It causes inefficiency in service provision (Pool, 2013), generates additional operational cost and consequently increases fuel consumption and emissions 
level (Hartman and Boscoianu, 2017). Moreover, within current European ATM system participate 37 ANSPs which operate 69 Area Control Centres (ACCs) of which 47 operate with 10 sectors or fewer at maximum configuration (Helios, 2006).

In some of reviewed papers authors have tried to define inefficiency cost of European ATM system caused by airspace fragmentation. Based on comparative analysis, it can be concluded that there is no consensus about how much really airspace fragmentation financially affects the European ATM system. For example, Matsoukis and Poulimenakos (Matsoukis and Poulimenakos, 2007) have estimated that fragmentation associated cost is EUR $880 \mathrm{~m}-1,400 \mathrm{~m}$, Grebenšek and Magister (Grebenšek and Magister, 2012) defined it to be around EUR 2-3 billion per year, while European Commission within its two documents gave two different estimations. According to Aviation Strategy for Europe (European Commission, 2015) the costs of fragmented airspace was estimated to be at least EUR 5 billion a year while in the Aviation: Open and Connected Europe document (European Commission, 2017) it was approximated to be at least EUR 3 billion a year. Additionally, some authors have analysed the causes of costs which arise due to fragmented design. For example, Van Antwerpen (Van Antwerpen, 2008) argues that cost multiplication caused by airspace fragmentation primarily relates to duplication of resources and costs associated with trainings, administration and Research and Development (R\&D). In that context, Steele (Steele, 2011) concludes that duplication of resources is irritating enough to the airlines because they are the ones financing provision of Air Traffic Services.
Although Chicago Convention states that every State has complete and exclusive sovereignty over the airspace above its territory (International Civil Aviation Organisation, 2001) that should not be the excuse for fragmented design of European airspace. Furthermore, it's important to understand that airspace fragmentation does not only refers to airspace division based on national boundaries. Accordingly, it's possible to define different airspace fragmentation types and their specifics. For example, O'Connell and Williams (O'Connell and Williams, 2016) define that fragmentation has its stronghold in existence of different stakeholder's business models - such as government budget/privatized, for-profit/non-for-profit, charges/no-charges etc. However, although they can differ, all airspace fragmentation types have in common that they can be characterised by three correlated features: studied feature and its accompanying temporal and spatial features.

Lastly, by summarizing most recently conducted studies (Fricke, 2019; Anton et al., 2019; Rezo and Steiner, 2019; Ruiz et al., 2019; Standfuß et al., 2019; Cannavicci and Eljon, 2019; Asthill et al., 2019; Buyle et al., 2019; Pavlović and Fichert, 2019), it's recognized that currently there is no unambiguous answers on question how to define and measure airspace fragmentation. Since European airspace fragmentation typology have not been so far comprehensively addressed, its better understanding can also lead to creation of new knowledge and identification of areas which require further research. Therefore, this paper in its below subsections defines the most important European airspace fragmentation types and their specifics. 


\section{Fragmentation Typology}

\subsection{Organizational Airspace Fragmentation}

In reviewed subject literature authors in great extent refer to fragmented design of European airspace by referring to its organizational division. Therefore, it's the first type described within the context of European airspace fragmentation typology. Besides that, it's important to understand organizational design of European airspace before proceeding to other fragmentation types.

The way airspace is organized has an extremely important role within European ATM system. Usually when authors mention airspace fragmentation, they primary refer to airspace division based on national boundaries. However, it's important to understand that it's just one aspect of organizational airspace fragmentation. From organizational aspect European airspace can be divided into different volumes. The appropriate way to define it is to place it in the context of airspace horizontal and vertical division. Horizontally it's divided into controlled airspace volume, airspace volume in which flight are specially regulated and uncontrolled airspace volume (Mihetec, 2017). Onwards organizational fragmentation includes further categorization of controlled airspace volume. It breaks down into differently sized areas such as Flight Information Regions (FIRs), Upper Flight Information Regions (UIRs), Control Areas (CTRs), Control Zones (CTRs) etc. On the other hand, vertical airspace division refers to separation of controlled airspace into multiple sectors such as Lower, Upper, High and Top sector. Figure 1 shows an example of vertical and horizontal view of organizational airspace fragmentation.

To sum up, organizational airspace fragmentation is a primarily results of the application of different airspace organizational related policies, strategies, rules, procedures and standards established with a view to ensure safe and coordinated flight operation. Additionally, this fragmentation type developed in parallel with the development of ATM system. It represents a quite apparent and consistent airspace fragmentation type. Furthermore, it represents an airspace fragmentation type which does not significantly vary, nor temporally nor spatially.

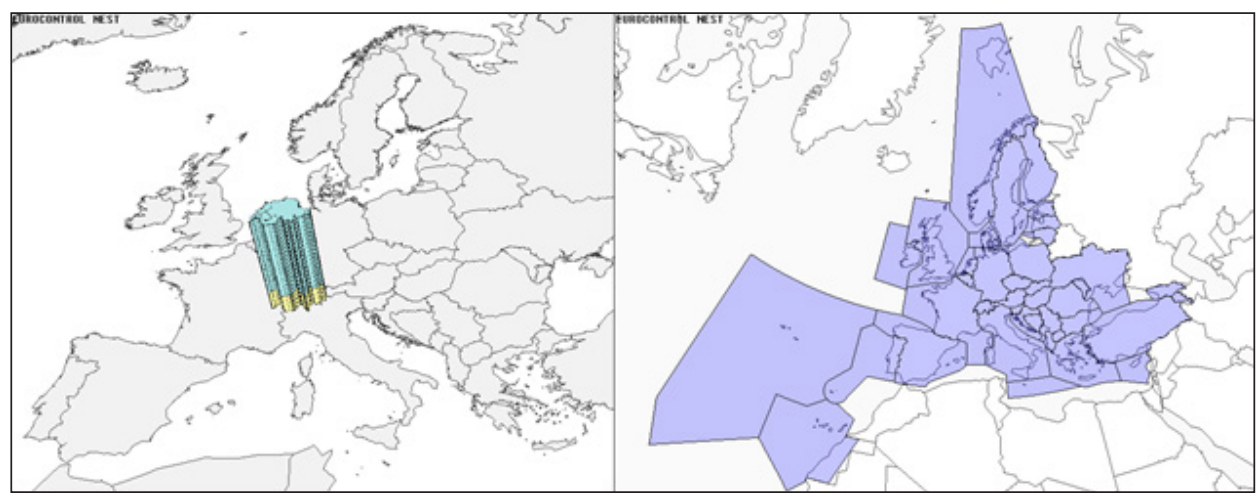

Fig. 1.

Spatial Overview of Organizational European Airspace Fragmentation 


\subsection{Operational Airspace Fragmentation}

Operational airspace fragmentation is closely related to organizational airspace fragmentation type. As the term suggests, it derives from the operational domain of the airspace management function. Some authors also refer to it as dynamic airspace type, study its configuration and suggest reconfigurations and re-sectorizations (Sergeeva et al., 2017; Zelinski and Lai, 2011; Tang et al., 2012). Operational fragmentation particularly refers to horizontal airspace division and controlled airspace volume in which flights are specially regulated. Moreover, it coincides with sovereignty right of every State to prohibit or restrict flights in parts of airspace volume (International Civil Aviation Organisation, 2006). So operational fragmentation can be seen by seceding areas which are categorized as Prohibited (P), Restricted (R), Dangerous (D), Temporary Segregated Areas (TSA) etc. (Wang et al., 2017).

Since airspace represents a limited resource, in order to make European ATM system more manageable and improve flight efficiency, at the operational level it was necessary to reduce negative effects associated with this airspace fragmentation type. In previous decades, operational fragmentation has negatively affected ATM system's efficiency. One of the reasons for that were airspace closure and flight routing restriction problems imposed by military operations (Mihetec et al., 2013). Although military airspace structures were closed for commercial flights, frequently they were not $\mathrm{H} 24$ operational (Steiner et al., 2019). Such a situation made air traffic flow management more complex and civilmilitary cooperation more difficult (Huang, 2009). Consequently, it affected increase of en-route delays, lack of airspace capacity and increased the operational costs of General Air Traffic (GAT).

Establishment of Single European Sky (SES) initiative imposed a need for a higher utilization level of military airspace areas which could be no longer operational H24 and unevenly used. Shift from permanent structures into dynamically manageable military airspace structures (shown by Figure 2) significantly reduced level of operational airspace fragmentation. This was primarily enabled by implementation of Flexible Use of Airspace (FUA) concept supported by Commission Regulation (EC) No. 2150/2005 (European Commission, 2005). The main idea behind FUA concept is to create an operationally manageable airspace structures which can be activated or deactivated at certain intervals and in such way subdivide the airspace between different categories of airspace users. Also, it's necessary to emphasize on-going implementation of Free Route Airspace concept at European level which is supported by Commission implementing Regulation (EU) 2019/123 (European Commission, 2019). Its deployment classifies specified airspace within which “...users can freely plan a route between a defined entry point and a defined exit point with the possibility of routeing via intermediate waypoints..." (Network Manager, 2016). These two concepts have particularly distinguished as good examples of how it is possible to improve flight efficiency regardless to fragmented design of European airspace. Their implementation has reduced fragmentation level what enabled minimization of negative environmental effects, airspace capacity improvements and flight efficiency enhancement. 


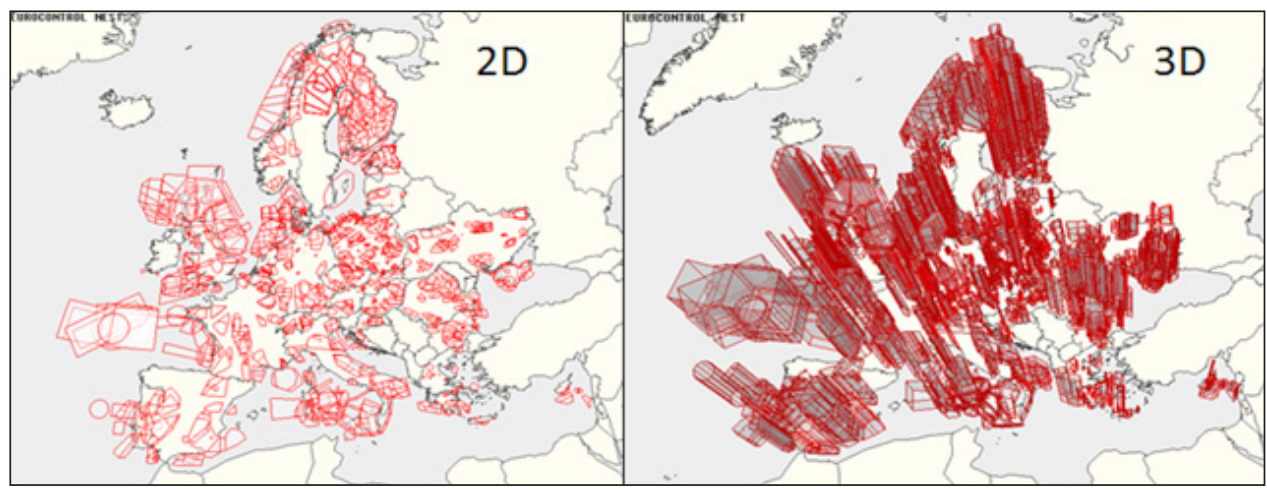

Fig. 2.

Spatial Overview of Operational European Airspace Fragmentation

To sum up, operational airspace fragmentation represents a quite familiar and apparent airspace fragmentation type with which airspace users and Air Traffic Control Officers (ATCOs) need to deal with on daily basis. Compared with other fragmentation types, it can be concluded that during last two decades the most noticeable effort to overcome airspace fragmentation was made in terms of operational defragmentation. Furthermore, it can be defined that operational airspace fragmentation type is characterized by high variability level of airspace structures allocation. Consequently, fragmentation level frequently differs from hour-to-hour or day-to-day operations. In that context, it can be concluded that this fragmentation type significantly temporally and spatially varies.

\subsection{Technical Airspace Fragmentation}

Technical airspace fragmentation represents a fragmentation type which is rarely placed in the foreground. It is characterized by market competitiveness of technical services, equipment and infrastructure provided by different Flight Data Processing
(FDP) and Radar Data Processing (RDP) system suppliers. In addition, it refers to highly technological surrounding operating under economic pressure with complex and dynamic interactions between different parties.

Incontestable right of every ANSP is to choose the best market offer for FDP and RDP systems. On the European level (which is characterized by market openness), that have led to scattered application of different FDP and RDP technologies. Such a situation has resulted with creation of technically based airspace fragmentation - shown by Figure 3. According to Baumgartner and Finger (Baumgartner and Finger, 2014), nowadays FDP and RDP system suppliers are faced up with only one market per country and hence their business logic has led to a tailor-made approach designed for every State/ANSP individually. Consequently, this has led to situations in which sometimes the neighbouring ANSPs have poorly interoperable systems. Result of that are series of handovers between neighbouring ANSPs which work with different technical systems (Arblaster, 2018). 


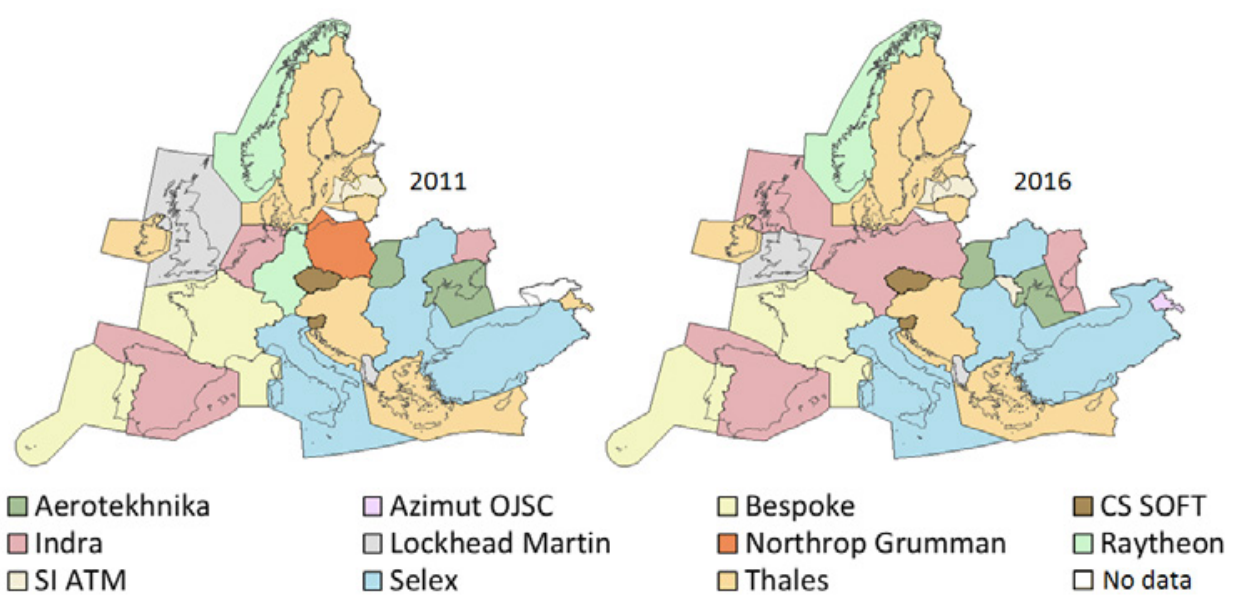

Fig. 3.

Temporal and Spatial Variability Overview of the Technical European Airspace Fragmentation Source: Own analysis based on reports Performance Review Unit, 2013; Performance Review Unit, 2016

Within previous decades there was none or very few initiatives for collaborative activities with an aim to mitigate technical aspect of airspace fragmentation. But unlike previous times, during past few years it's possible to notice different moves towards common technical related procurements. In addition, nowadays technical and technological solutions also permit a higher degree of centralised management and maintenance of FDP and RDP systems. However, it's important to point out that such initiatives, with the guise of their aim to reduce this type of airspace fragmentation, threaten different vested interests and are frequently faced with opposition. So, it can be concluded that FDP and RDP system suppliers have no interest in the harmonization of the ATM services, equipment and infrastructure because, if that occurs, most likely some of suppliers would disappear from market. Considering mentioned it's expected that technical airspace fragmentation will not be markedly changed over the following years. Also, based on previous experiences it can be only expected that certain market differences will arise with a given time lapse.

\subsection{Functional Airspace Fragmentation}

Functional airspace fragmentation represents frequently mentioned and depicted type which has slightly spatially and temporally changed. It's conditionally determined and politically supported airspace fragmentation type. This mainly refers to the fact that this airspace division is determined by European Commission and defined by SES initiative's legislation. The idea behind this artificially created fragmentation type is to booster airspace reorganization through the application of Functional Airspace Blocks (FABs) (Cook et al., 2017). FAB represent an airspace block which is based on operational requirements, reflecting the need to ensure more integrated management of the airspace regardless of existing national boundaries (Alam et al., 2017). Also, Functional Airspace 
Blocks represent a tool for reduction of airspace fragmentation while at the same time they should increase the overall European
ATM system's efficiency (Button and Neiva, 2013). Figure 4 shows a foreseen approach of vertical functional airspace reorganization.

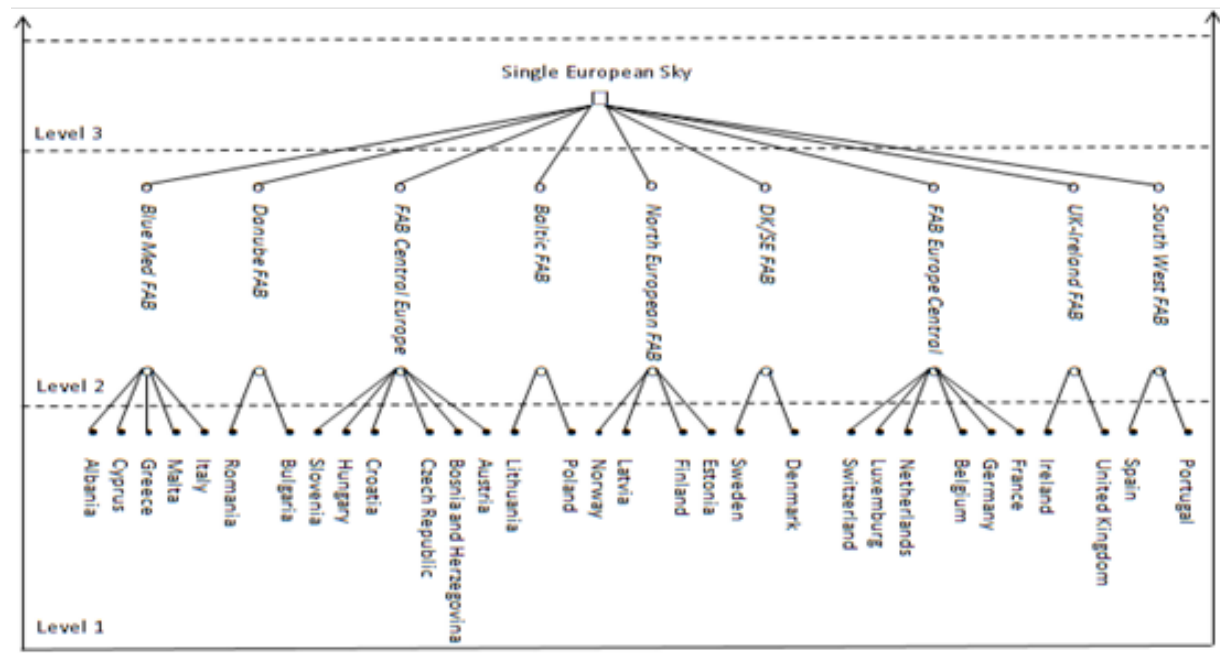

Fig. 4.

Vertical View of European Airspace Functional Reorganization

Although fragmentation affects all European ATM stakeholders, defragmentation process is inconspicuous (Franklin, 2007). In this context also Fox (Fox, 2016) argues that the states are reluctant to tackle airspace fragmentation. Furthermore, that is the reason why Jaffe (Jaffe, 2016) describes Europe as a "jigsaw puzzle of independent national airspaces" while Steiner et al. (Steiner et al., 2010) argue that the fragmentation problem should be solved by the comprehensive dynamic harmonization programs. In addition, by comparing functional airspace fragmentation (idea of FABs) its aim is actually to defragment organizational airspace division. But, by considering currently achieved progress in the sense of FABs establishment, it's evident that even though the planning of the SES initiative is based on the collaborative FABs implementation, the real implementation is fragmented and based on national levels (Mihetec et al., 2017). Moreover, considering how many years have elapsed since European Commission launched the SES initiative it's obvious that European ATM community too long tries to make a step from functional Level 1 to Level 2. With such a slow progress and partial efforts, it's hard to predict whether and when the transition to third functional level is going to happen. Therefore, International Air Transport Association argued that development of FABs is unacceptably slow and passive and that FABs haven't optimized airspace along air traffic flows nor human nor technical resources (International Air Transport Association, 2017). Figure 5, unlike previous figure, shows the spatial overview of foreseen functional airspace reorganization process from which it can be seen spatial distribution of FABs and differences between their spatial sizes. 


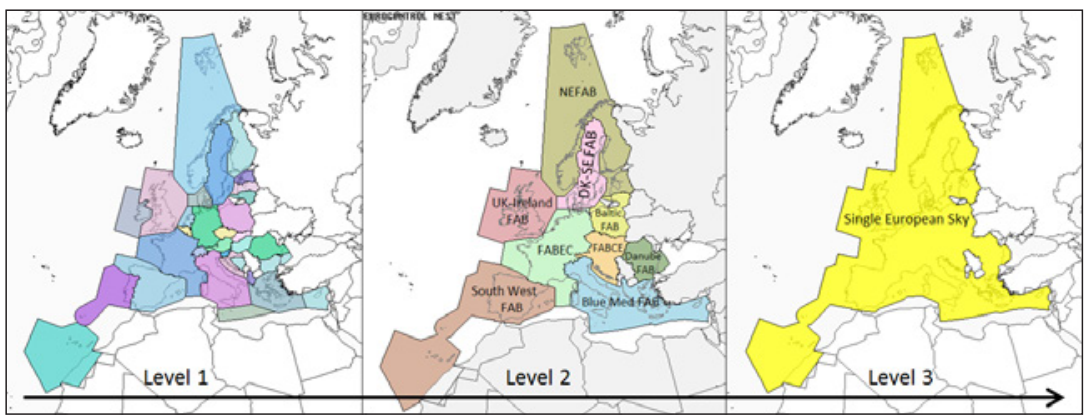

Fig. 5.

Spatial Overview of European Airspace Functional Reorganization

\section{Discussion}

Although different regulations and projects are already trying to reduce European airspace fragmentation, there are still a lot of areas which need to be better study. That can be achieved by providing answers on few simple questions; why, when and where? In that context, from the research point of view it can be found that a lot of work still needs to be done. There is no doubt that the forthcoming period will require sustained efforts to improve safety, increase airspace capacity and enhance the efficiency of the European ATM system. Hence, it's mandatory to conduct a strategic planning with aim of better understanding European ATM system's strengths, weaknesses, opportunities and threats.

When considering conduction of strategic planning of air transport development, it's necessary to bear in mind that it is influenced by different external and internal factors (Steiner et al., 2008). In addition, strategic modelling of air transport development shouldn't be only indicated by transport networks' technical elements nor the handled transport volume, but rather by terms of availability or connectivity (Steiner et al., 2014). Hence, when valuing the current state or determining projections of air traffic development it's important to include different factors - ranging from ecologic to economic impacts (Steiner et al., 2008). Especially because their strategic planning can lead to reduction of delays and costs (Bolić et al., 2017). In that context, it can be distinguished one more airspace fragmentation type. As a fifth airspace fragmentation type it's possible to define performances-based airspace fragmentation. It is result of partial interactions of previously defined fragmentation types. Considering mentioned and by comparing its characteristics with earlier defined types, it's possible to determine similarities and differences between them - and so draw out conclusion about this type of airspace fragmentation. On the one hand, the previously defined fragmentation types are largely permanent and defined by global, regional or national regulations, acts, standards or treaties. Unlike to most of them, performances-based airspace fragmentation is more variable. On the other hand, all types have in common that they are mostly under jurisdiction and direct responsibility of Civil Aviation Authorities, i.e. National Supervisory Authorities as it is defined by Regulation (EC) No 549/2004 (European Commission, 2004).

Considering the spatial and temporal variability of air traffic flow in Europe (Young et al., 2009) it's mandatory to continuously 
look for improvements which will mitigate the negative effects on European air traffic market. Hence, second package of Single European Sky initiative introduced the performance measurement scheme (Steiner et al., 2013) which is driven by four Key Performance Areas (KPAs): environment, cost-efficiency, safety and capacity. It represents one of absolute conditions for the very existence of safe and efficient air transport (McMillyn and Van Dam, 2011). Its aim is to ensure efficiency improvements by providing better service quality at lower cost (Steiner et al., 2014) and to minimize negative impacts arising from performance variability. In addition, performance measurement is inevitable, useful and necessary (Hatry, 2006). It can play an important role in understanding why unexpected or undesired outcomes occurred and how to improve system's efficiency. Beechener (Beechener, 2018) argues that the challenge of current ATM system is to accommodate different types of traffic demand which is driven by short-term effects. Mentioned primarily refers to the fact that within last decade variations in traffic demand, routes flown and unexpected flight profiles in Europe are occurring more frequently than before (FABEC, 2018). Also, increased traffic variability has led to creation of current situation in which ATM resources are sometimes underutilized. Therefore, considering that performance variations have a direct impact on ANSP's operational and financial resources, European ATM community's goal should be to minimize the effects of performance variability.

By analysing literature cited so far, it was found out that significant volume of work has been done to study design, characteristics and performances of European ATM system. However, most of the sources do not correlate temporal and spatial domain of its development. Usually they omitted spatial and define only performances' temporal and value features. In that context, Figure 6 shows an example of aforementioned where variability overview of temporal and value features is based on Central Route Charges Office's and Performance Review Unit's data. Figure shows some of Key Performance Indicators and their variability on the European level in relation to air traffic growth from 2014 till end of 2018.
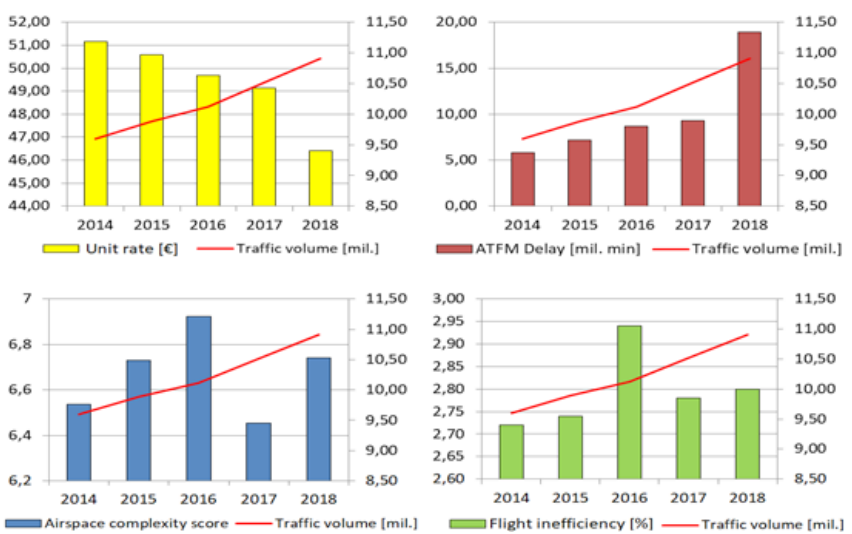

Fig. 6 .

Temporal and Value-based Overview of European Airspace Performances Variability

Source: Own analysis based on dataset originated from EUROCONTROL, 2019; Performance Review Unit, 2019 
Since performance measurement is one of mechanisms for achieving development of European ATM system, it's crucial to understand correlation in-between its features. In that context, Figure 6 shows an example of averaged annual performances variability of European ATM system where unit rate values, en-route Air Traffic Flow Management (ATFM) delay values, airspace complexity score values and horizontal enroute flight inefficiency values were used. Considering that in this way only two of three features are defined, there was a loss of spatial information.

In order to comprise all features, it's necessary to define basic methodological concept (Steiner et al., 2015). So, with a goal to define performances-based airspace fragmentation, it's necessary to correlate all three - value, temporal and spatial features. Since ATM research and development relies heavily on simulation methods (Radašić et al., 2015) within future research it would be useful to develop a methodological approach, preferably integrated into analytical tool, which could help to monitor performances-based airspace fragmentation level. Additionally, such a methodological approach should be designed with ability to capture performance variability and to indicate areas which require performance improvements. Expected result of methodological improvements should be also creation of a consistent assessment tool able to identify areas in which by only minor efforts a significant benefit can be expected. To summarize, definition of performancesbased airspace fragmentation level should be methodologically approached in such way that it includes performance values of whole European ATM network thus enabling consistent planning at the national and regional level.

\section{Conclusion}

The problem of fragmented design of European airspace has been known for a long time and in various ways over the past decades it has been tried to be resolved. Primarily reason for that is fact that airspace fragmentation negatively affects the efficiency level of European ATM system.

This paper has provided literature review on highly actual topic of European airspace fragmentation. It resulted with identification of five airspace fragmentation types of which four types were wholly depicted. Similarities and differences between defined types were also determined. It has been found out that some fragmentation types are more apparent than others and thus more frequently studied. Furthermore, certain fragmentation types began to appear more lately than other types. In addition, some fragmentation types are largely permanent while some are more variable.

Considering the forecasts about future increase of air traffic over European airspace, it is important to continuously look for improvements which will mitigate the negative effects caused by inefficient European airspace design. Scarcity of information that would help European ATM community might be seen also as one of causes for the lack of focus for collaborative initiatives on fragmentation issues. Therefore, this research was carried out with the aim to define European airspace fragmentation typology and identify issues that might be needed to be addressed within future research. In that context, it's possible to define that there are no sources which spatially correlate performances in relation to airspace fragmentation. Hence it would be useful to study this issue more in-depth 
and so help European aviation community to better understand its business environment. Conclusively such studies should be able to give information primarily useful within domain of strategic planning of European ATM system.

\section{References}

Alam, S.; Chaimatanan, S.; Delahaye, D.; Feron, E. 2017. A Distributed Air Traffic Flow Management Model for European Functional Airspace Blocks. In Proceedings of the $12^{\text {th }}$ USA/Europe ATM R\&D Seminar, 1-10.

Alemanno, A. 2010. The European Regulatory Response to the Volcanic Ash Crisis between Fragmentation and Integration, European Journal of Risk Regulation 1(2): 101-106.

Anton, R.; Lokman, N.; Pitton, E.; Whittome, M. 2019. Is fragmentation a sin?. In Proceedings of the Research Workshop Fragmentation in Air Traffic and its Impact on ATM Performance, 14-22.

Arblaster, M. 2018. Air Traffic Management: Economics, Regulation and Governance. Elsevier. The Netherlands. 286 p.

Asthill, J.; Stoyanow, V.; Fichert, F. 2019. Fragmentation in the European upper airspace? A cost-benefit approach to harmonisation. In Proceedings of the Research Workshop Fragmentation in Air Traffic and its Impact on ATM Performance, 96-102.

Baumgartner, M.; Finger, M. 2014. The Single European Sky gridlock: A difficult 10 year reform process, Utilities Policy 31: 289-301.

Beechener, J. 2018. Volatility in Air Traffic Management - Europe Tackles Growth in Traffic Volatility, The Journal of Air Traffic Control 60(3): 46-50.

Bolić, T.; Castelli, L.; Corolli, L.; Rigonat, D. 2017. Reducing ATFM delays through strategic flight planning, Transportation Research Part E Logistics and Transportation Review 98: 42-59.

Budd, L.; Ison, S. 2016. Air Transport Management: An international perspective. Taylor \& Francis. USA. 394 p.

Button, K.; Neiva, R. 2013. Single European Sky and the functional airspace blocks: Will they improve economic efficiency?, Journal of Air Transport Management 33: 73-80.

Button, K. 2001. Deregulation and Liberalization of European Air Transport Markets, The European Journal of Social Science Research 14(3): 255-275.

Buyle, S.; Dewulf, W.; Kupfer, F.; Onghena, E.; Meersman, H.; Van de Voorde, E. 2019. How ANSP business model developments can contribute to the defragmentation of the European ANS landscape. In Proceedings of the Research Workshop Fragmentation in Air Traffic and its Impact on ATM Performance, 104-114.

Cannavicci, C.; Eljon, M. 2019. FABs and fragmentation - where is the added value?. In Proceedings of the Research Workshop Fragmentation in Air Traffic and its Impact on ATM Performance, 66-74.

Cook, A.; Belkoura, S.; Zanin, M. 2017. ATM performance measurement in Europe, the US and China, Chinese Journal of Aeronautics 30(2): 479-490.

Cook, A. 2016. European Air Traffic Management: Principles, Practice and Research. Routledge. USA. 260 p.

Dobruszkes, F.; Van Hamme, G. 2011. The impact of the current economic crisis on the geography of air traffic volumes: an empirical analysis, Journal of Transport Geography 19(6): 1387-1398.

EUROCONTROL. 2019. Monthly Adjusted Unit Rates Database. Available from internet: <https://www. eurocontrol.int/services/monthly-adjusted-unit-rates $>$.

European Commission. 1996. Air Traffic Management Freeing Europe's airspace. Belgium. 116p. 
European Commission. 2015. An Aviation Strategy for Europe. Belgium. 16 p.

European Commission. 2017. Aviation: Open and Connected Europe. Belgium. 7 p.

European Commission. 2005. Regulation (EC) No 2150/2005 of 23 December 2005 laying down common rules for the flexible use of airspace. Belgium. 6 p.

European Commission. 2004. Regulation (EC) No 549/2004 of the European Parliament and of the Council of 10 March 2004 laying down the framework for the creation of the single European sky. Belgium. 8 p.

European Commission. 2019. Regulation (EU) No 2019/123 of 24 January 2019 laying down detailed rules for the implementation of air traffic management (ATM) network functions. Belgium. $45 \mathrm{p}$.

European Commission. 2019. Single European Sky. Available from internet: <https://ec.europa.eu/ transport/modes/air/ses_en $>$.

European Court of Auditors. 2017. Single European Sky: a changed culture but not a single sky. European Union. Luxembourg. 71 p.

Finger, M.; Button, K. 2017. Air Transport Liberalization: A Critical Assessment. Edward Elgar Publishing. United Kingdom. 400 p.

Fox, J. 2016. Single European Skies: Functional Airspace Blocks - Delays and responses, Air and Space Law 41(3): 201-227.

Franklin, M. 2007. Sovereignty and Functional Airspace Blocks, Air and Space Law 32(6): 425-430.

Fricke H. 2019. Impact of Fragmentation on ATM System Performance. In Proceedings of the Research Workshop Fragmentation in Air Traffic and its Impact on ATM Performance, 6-12.
Functional Airspace Block Europe Central. 2019. ATM in Europe - It's all about performance. Available from internet: <https://www.fabec.eu/images/user-pics/pdfdownloads/FABEC_All_about_Performance_1.pdf $>$. Functional Airspace Block Europe Central. 2018. Volatility in ATM: Cases, Challenges, Solutions. World ATM Congress. Spain. 24 p.

Getimēs, P.; Kaukalas, G. 2007. Overcoming Fragmentation in Southeast Europe: Spatial Development Trends and Integration Potential. Ashgate Publishing. United Kingdom. 354 p.

Grebenšek, A.; Magister, T. 2012. Traffic variability in benchmarking of Air Navigation Service Providers cost-effectiveness, International Journal for Traffic and Transport Engineering 2(3): 185-201.

Hartman, N.; Boscoianu, M. 2017. Single European Skythe transformation of the aviation industry based on the dynamic capabilities, INCAS BULLETIN 7(1): 97-109.

Hatry, H. 2006. Performance Measurement: Getting Results. The Urban Institute Press. USA. 342 p.

Helios. 2006. The impact offragmentation in European ATM/ CNS. EUROCONTROL. Belgium. 140 p.

Huang, J. 2009. Aviation Safety through the rule oflaw: ICAO's mechanisms and practices. Kluwer Law International. The Netherlands. 265 p.

International Air Transport Association. 2017. A Blueprint for the Single European Sky: Delivering on safety, environment, capacity and cost-effectiveness. Canada. $24 \mathrm{p}$.

International Civil Aviation Organisation. 2006. Convention on International Civil Aviation: Doc 7300/9. Canada. 114 p.

International Civil Aviation Organization. 2001. Air Traffic Services Annex 11. Canada. 80 p. 
Jaffe, S. 2016. Airspace Closure and Civil Aviation: A Strategic Resource for Airline Managers. Routledge. USA. 302 p.

Janić, M. 1997. Liberalisation of European aviation: analysis and modelling of the airline behaviour, Journal of Air Transport Management 3(4): 167-180.

Kawagoe, M., 2008. Air Transport Deregulation in the EU: Study from the Europeanization Perspective. In Proceedings of the IPSA Symposium on European Integration between the Past and the Present, 161-180.

Macário, R.; Van de Voorde, E. 2009. The impact of the economic crisis on the EU air transport sector. European Parliament's Committee on Transport and Tourism. Belgium. 37 p.

Matsoukis, E.; Poulimenakos, S. 2007. Air traffic management in the South East European countries. Current situation and prospects, European Transport 37: 16-34.

McMillyn, D.; Van Dam, R. 2011. EUROCONTROL and the EU Single European Sky. In Crespo, D.; Mendes de Leon, P. (eds.) Achieving the Single European Sky: Goals and Challenges. Kluwer Law International, The Netherlands. 67-78.

Mihetec, T.; Steiner, S.; Odić, D. 2013. Utilization of Flexible Airspace Structure in Flight Efficiency Optimization, Promet - Traffic\& Transportation 25(2): 109-118.

Mihetec, T.; Vidović, A.; Rezo, Z. 2017. Assessment of Single European Sky Implementation in the Functional Airspace Block Central Europe, Promet - Traffic \& Transportation 29(6): 643-655.

Mihetec, T. 2017. Air Traffic Management. Faculty of Transport and Traffic Sciences, Croatia. p.

Nava-Gaxiola, C.; Barrado, C. 2016. Performance measures of the SESAR Southwest functional airspace block, Journal of Air Transport Management 50: 21-29.
Neiva, R. 2015. Institutional Reform of Air Navigation Service Providers: A Historical and Economic Perspective. Edward Elgar Publishing. United Kingdom. 192 p.

Network Manager. 2018. European Route Network Improvement Plan-Part 3: Airspace Management Handbook: Guidelines for Airspace Management. EUROCONTROL. Belgium. 320p.

Network Manager. 2016. Free Route Airspace developments. EUROCONTROL. Belgium. 32 p.

O’Connell, J.; Williams, G. 2016. Air Transport in the 21st Century: Key Strategic Developments. Routledge. USA. $512 \mathrm{p}$.

Oster, C.; Strong, J. 2017. Managing the Skies: Public Policy, Organization and Financing of Air Traffic Management. Routledge. USA. 240 p.

Ozmec Ban, M.; Škurla Babić, R. 2018. European air transport market under influence of cooperative arrangements. In Proceedings of the Fourth International Conference on Traffic and Transport Engineering, 38-43.

Pavlović, G.; Fichert, F. 2019. Effects of fragmentation on route charges - status quo analysis and potential alternatives. In Proceedings of the Research Workshop Fragmentation in Air Traffic and its Impact on ATM Performance, 117-124.

Performance Review Unit. 2013. ATM Cost-Effectiveness (ACE) 2011 Benchmarking Report with 2012-2016 outlook. EUROCONTROL. Belgium. 200 p.

Performance Review Unit. 2016. ATM Cost-Effectiveness (ACE) 2016 Benchmarking Report with 2017-2021 outlook. EUROCONTROL. Belgium. 222 p.

Pool, R. Organization and Innovation in Air Traffic Control. 2013. Hudson Institute Initiative on Future Innovation. USA. 59 p. 
Performance Review Unit. 2019. Database. Available from internet: <http://ansperformance.eu/>.

Radišić, T.; Novak, D.; Juričić, B. 2015. Development and Validation of an ATC Research Simulator. In Proceedings of International Conference on Air Transport, 1-10.

Rezo, Z.; Steiner, S. 2019. European airspace complexity and fragmentation correlation research. In Proceedings of the Research Workshop Fragmentation in Air Traffic and its Impact on ATM Performance, 31-38.

Ruiz, S.; Kadour, H.; Choroba, P. 2019. Network delay optimisation of multiple CASA regulations in fragmented European airspace. In Proceedings of the Research Workshop Fragmentation in Air Traffic and its Impact on ATM Performance, 23-30.

Schultz, M.; Lorenz, S.; Schmitz, R.; Delgado, L. 2018. Weather Impact on Airport Performance. Aerospace 5(4): 1-19.

Sergeeva, M.; Delahaye, D.; Mancel, C.; Vidosavljević A. 2017. Dynamic airspace configuration by genetic algorithm, Journal of Traffic and Transportation Engineering $4(3): 300-314$

SESARJoint Undertaking. 2019a. Projects. Available from internet: <https://www.sesarju.eu/activities-projects $>$.

SESAR Joint Undertaking. 2019b. A proposal for the future architecture of the European airspace. Belgium. 159 p.

Skyway Magazine. 2018. Challenges of Growth. EUROCONTROL. Belgium. 56 p.

Standfuß, T.; Fichert, F.; Schultz, M.; Stratis, P. 2019. Efficiency losses through fragmentation? Scale effects in European ANS provision. In Proceedings of the Research Workshop Fragmentation in Air Traffic and its Impact on ATM Performance, 57-65.
Stankūnas, J.; Kondroška, V. 2012. Formation of methodology to model regional airspace with reference to traffic flows, Aviation 16(3): 69-75.

Steele, P. 2011. SES Environmental and Efficiency Benefits: Reduction of Emissions. In Crespo D., Mendes de Leon, P. (eds.) Achieving the Single European Sky: Goals and Challenges. Kluwer Law International. The Netherlands. 167-178 p.

Steiner, S.; Božičević, A.; Mihetec, T. 2008. Determinants of European air traffic development, Transport Problems 3(4): 73-84.

Steiner, S.; Feletar, P.; Šimecki, A. 2014. Transport and spatial correlation of regional development. In Proceedings of $6^{\text {th }}$ International Maritime Science Conference 505-517.

Steiner, S.; Galović, B.; Radačić, Ž. 2008. Strategic Framework of Air Traffic Development, Promet Traffice Transportation 20(3): 157-167.

Steiner, S.; Mihetec, T.; Božičević, A. 2010. Prospects of Air Traffic Management in South Eastern Europe, Promet - Traffice Transportation 22(4): 293-302.

Steiner, S.; Mihetec, T.; Modić, A. 2013. Performance based air navigation services. In Proceedings of International Conference on Air Transport, 120-125.

Steiner, S.; Mihetec, T.; Rezo, Z. 2019. Resolution of operational constraints imposed by fragmentation of European airspace. In Proceedings of the International Scientific Conference: Science and Traffic Development, 385395.

Steiner, S.; Šimecki, A.; Ljubojević, S. 2015. Air transport connectivity scenario of regional development. In Proceedings of $17^{\text {th }}$ International Conference on Transport Science, 460-473. 
Steiner, S.; Štimac, I.; Melvan, M. 2014. Towards to Collaborative Air traffic and Airport Management. In Proceedings of the $22^{\text {nd }}$ International Symposium on Electronics in Transport: ITS for Seamless and Energy Smart Transport, 1-7.

Szalai, M. 2018. The crisis of the GCC and the role of the European Union. European Union. 8 p.

Tang, J.; Alam, S.; Lokan, C.; Abbass, H. 2012. A multiobjective approach for Dynamic Airspace Sectorization using agent based and geometric models, Transportation Research Part C: Emerging Technologies 21(1): 89-121.

Van Antwerpen, N. 2008. Cross-Border Provision of Air Navigation Services with Specific Reference to Europe: Safeguarding Transparent Lines of Responsibility and Liability. Kluwer Law International. The Netherlands. 276 p.
Wang, S.; Cao, X.; Li, H.; Li, Q.; Hang, X.; Wang, Y. 2017. Air route network optimization in fragmented airspace based on cellular automata, Chinese Journal of Aeronautics 30(3): 1184-1195.

Young, D.; Pilon, N.; Brom, L. 2009. Challenges of Air Transport 2030: Survey of experts' views. EUROCONTROL. Belgium. 64 p.

Zelinski, S.; Lai, F. 2011. Comparing methods for dynamic airspace configuration. In Proceedings of $30^{\text {th }}$ Digital Avionics Systems Conference, 1-10.

\section{jitte 30}

